\title{
FACILITY MAINTENANCE AND MANAGEMENT: A HEALTH CARE CASE STUDY
}

\author{
Igal M. SHOHET a, Sarel LAVY b \\ ${ }^{a}$ Department of Structural Engineering, Ben-Gurion University of the Negev, P.O.B. 653, Beer-Sheva \\ 8410501, Israel \\ ${ }^{b}$ Department of Construction Science, Texas A\&M University, College Station, TX 77843-3137, USA
}

Received 6 April 2015; accepted 6 May 2016

\begin{abstract}
Contemporary trends in healthcare services provision tend toward the increased use of community based healthcare centers. This study on the concepts of healthcare provision hypothesizes that in the future, the main source of healthcare services will be a network of community based clinics which will be responsible for the majority of primary and ambulatory care. This concept implies that a network of community clinics equipped with state of the art telemedicine will be established with a wide geographical dispersion. The implications for healthcare facilities in terms of the resources and performance of the built environment are investigated by reference to the Israeli healthcare system. This paper reflects the results of research on healthcare facility management over the past 10 years. Comparison of the performance and maintenance of hospital facilities and community clinics reveals that the maintenance and performance of clinic facilities have the potential to combine improved healthcare facility services with cost-effective facility management and maintenance.
\end{abstract}

KEYWORDS: Facility management; Healthcare; Key performance indicators; Maintenance; Close care

SUPPLEMENTARY MATERIAL associated with this article can be found, in the online version, at https://10.3846/1648715X.2016.1258374

\section{INTRODUCTION}

Countries all over the world are witnessing similar trends in the provision of healthcare services with an increase in the demand for healthcare in public hospitals triggered by natural population growth, the ageing of the population, and the consumer revolution (Hosking, Jarvis 2003). Consequently, the total number of in- and out-patient admissions per 1,000 inhabitants has also increased (American Hospital Association 2010), and hospitals have responded by a tendency to reduce patients' average length of stay in order to husband their limited resources. Evidence for this trend has been reported independently in Germany (Federal Statistical Office Germany 2003) and the U.K. (Hensher, Edwards 1999). In the U.S., a $14.2 \%$ increase in the number of in-patient admissions in community hospitals was recorded between 1994 and 2004, together with a decrease of $16.4 \%$ in the average length of stay. Concomitantly, an increase of al-

* Corresponding author. E-mail: igals@bgu.ac.il most $50 \%$ in the number of out-patient admissions was observed in the exact same hospitals, with a significant increase of about $170 \%$ in the number of out-patient admissions over a period of 20 years (1984-2004) (American Hospital Association 2010). These changes have resulted in a demand for an investigation of the structure of healthcare systems and Facility Management (FM) decisionmaking processes in the industry. As an example, Melin and Granath (2004), conducted a study in Sweden on the effect of "Horizontal Integrated Care" (HIC), which deals with ways in which care is delivered to patients. This study investigated the management of healthcare facilities and the implications of HIC, "local hospitals", and "close care" on the built environment. Rees (1997, 1998) examined the development of the FM profession within the National Health Services (NHS) in the U.K., and discovered that NHS Trusts tend to integrate non-core services (e.g. risk management, energy efficiency, cleaning, security, etc.) under the umbrella of the FM department. It was also 
observed that in only $24 \%$ of the Trusts, was the senior FM director a board level executive member.

A scarcity of resources is immediately apparent when facility management in the healthcare sector is examined (American Hospital Association 2004; Federal Statistical Office Germany 2003). This might adversely affect the non-core activities of healthcare providers, and particularly aspects of the facility management, such as maintenance activities and operations. The American Hospital Association stated in the 2003 Annual Report that "Hospitals have been under financial pressure in the last five years, both from public and private payers. Since 1999, up to one third of hospitals have had negative total margins" (American Hospital Association 2006). A similar state of affairs is presented in the 2003 Annual Report of the British Ministry of Finance, which stated that: "Over the past 30 years the U.K. has consistently invested a smaller share of its national income in healthcare than comparator countries. Historical underinvestment has resulted in poorer health outcomes than the EU average" (British Ministry of Finance 2003).

Resource allocation in the healthcare sector is reflected in several health indicators published by the World Bank. These classify each country in the world according to average income level and regional categories (World Bank 2012). Two of the most interesting indicators are health expenditure per capita (in $\$$ U.S.) and total health expenditure as a percentage of Gross Domestic Product (GDP). The level of these two indicators in Israel where the 2009 health expenditure per capita was $\$ 1,966$, and the total health expenditure as a percentage of the GDP was $7.6 \%$, is comparable to many EU members, and higher than in most Asian, African, and South American countries. For comparison, the average health expenditures of the European Monetary Union countries and of the United States were $10.3 \%$ and $15.3 \%$ of the GDP respectively (World Bank 2012). This indicates a commitment on the part of Israeli policy-makers to provide quality healthcare to their people, which has been realized by a steady and continuous rise in life expectancy over the past 30 years (Brodsky 2003; World Bank 2012). The life expectancy of the Israeli population is consistently placed among the top 10 countries in the world, indicating the success of assuring a solid improvement of healthcare for Israeli citizens (World Health Organization 2012). An examination of the efficiency of this system may offer useful insights into which facility management practices, have contributed to the success of the health outcome.

In response to a steady demand to provide healthcare in distant peripheral regions, the Israeli healthcare system has developed a network of clinics organized in a hierarchical scheme. This network is composed of three levels of clinics (Fig. 1): community, regional and hospital-based. Community clinics are located in any city, town or village, and are approximately $500-2,500 \mathrm{~m}^{2}$ in size (mean size of $1,200 \mathrm{~m}^{2}$ ). In the entire country, there exist 1,000 community clinics that provide close ambulatory and primary care to an average of 8,000 insurance subscribers per clinic. Forty regional clinics support the community clinics, providing secondary care such as MRI, X-Ray, medical consultancy and regional laboratories that supply diagnostic services to both community and regional clinics. This network acts as a screening net that provides primary care to all patients insured in the Israeli system, prior to admission into a peripheral or regional hospital. Hospitals are classified into three categories of infrastructure and medical care: peripheral hospitals (less than 400 patient beds), regional hospitals (401-800 patient beds) and strategic hospitals that provide unique specified care and are equipped with built and human medical infrastructure (801-1,500 patient beds).

As discussed for other countries, the demands on the Israeli healthcare services have risen in recent years, with acute-care hospitals experiencing an increased number of in-patient admissions. One of the possibilities for dealing with this increased demand on resources is to develop a network of community clinics with the aim of providing close ambulatory and primary care, as well as diagnostic and specialty services. Although the use of com-

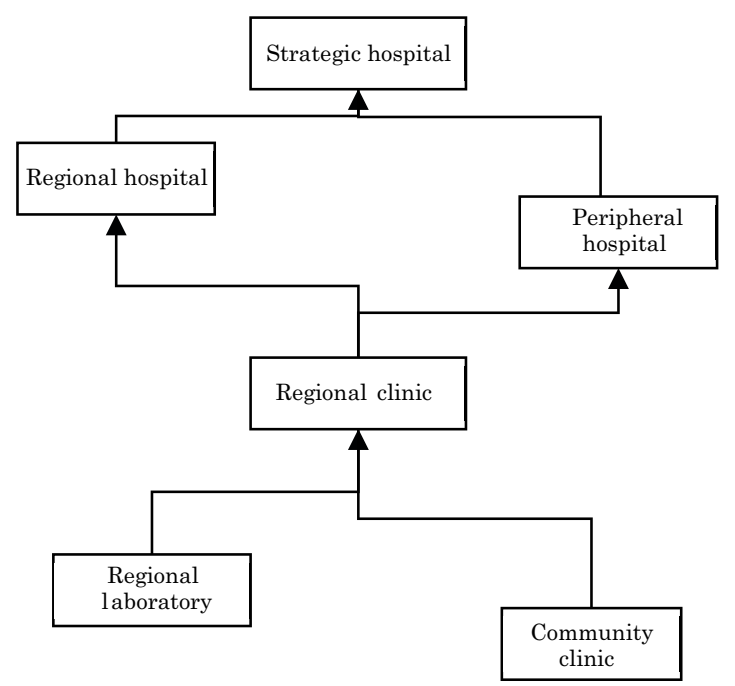

Fig. 1. Architecture of healthcare facilities 
munity clinics is increasingly common worldwide, the quality of care they provide is a subject of continuing debate (Fox et al. 2007; Scott et al. 2004). The past decade has seen much investigation and discussion of the quality and effectiveness of medical services in the medical research arena. Hutchison et al. (2003) compared the delivery of care to patients in walk in clinics with the more usual care given in emergency department and family practices. The overall quality of care in clinics was found to be equal to that received in emergency departments and higher than in family practices. Fox et al. (2007) examined the implementation of asthma-related community care of patients in an ethnically and geographically disparate population of economically disadvantaged school-aged children, and found that the clinic strategy provided a cross sectional improvement in medical care as well as in patient satisfaction. Community clinics were also shown to be effective for the delivery of primary care, and acute condition appointments (Coelho 2011; Qu, Shi 2009).

The core business for the healthcare sector can be defined as patient care, the primary objectives of FM departments in healthcare facilities should be to support the core business and not only to reduce costs. Ciarapica et al. (2008) defined the objectives of the maintenance of health facilities as high continuity (availability) and high functional safety levels, mainly related to the possible risks of failure.

In the literature only a few research studies have investigated the performance of FM in the healthcare sector, and then generally not from a quantitative aspect. Talib et al. (2013) assessed the performance of healthcare buildings through three criteria: (1) functionality, covering the design, utility and access of the facilities, (2) impact, covering the outlook, core activities, facilities, and future design assessment, and (3) quality related to the building, engineering activities, performance, and energy. They concluded that design of the building (for functionality), outlook of the facilities (for impact), and quality of the buildings (for quality) are the most important factors for the performance assessment of healthcare facilities.

Lega et al. (2013) analyzed the performance of a network supply chain strategy for the healthcare sector and discovered: (1) a significant reduction in operational costs, (2) financial benefits in terms of price reduction and supply management and (3) a significant improvement in the supply chain itself (high level of standardization and reliability). The research study reported by Cingolini et al. (2008) described the FM in small and medium enterprises in Italy, and analyzed two medium hospitals located in the north of the country. However also in this case, the research focused on the definition of the gap between the actual and desired performance from a qualitative point of view.

According to Lavy et al. (2014a, 2014b) an effective measure of the performance of a building necessitates the identification of a set of key performance indicators (KPIs) specific for the facility under consideration. These KPIs should: (1) be quantifiable, (2) be easily measurable, and (3) demonstrate wide applicability.

The present study investigates the FM characteristics of built healthcare facilities through a comparative investigation of the FM KPIs defined for a sample of 20 acute-care hospitals, and 42 community clinics. The paper discusses the implications of the performance, maintenance and benefit-to-cost ratio for any discrepancy between the allocation of resources in the development of built facilities for healthcare and the actual performance delivered.

\section{ALTERNATIVE HEALTHCARE SERVICE PROVISION}

The Israeli health sector encompasses a total number of 42,119 patient beds (Central Bureau of Statistics in Israel 2009), of which 50\% are designated for long-term care, and 35\% for acute-care. Furthermore, $70 \%$ of the total patient beds in Israel are publicly owned, whereas only $30 \%$ are private. In the acute-care sector, the share of the publiclyowned beds is even higher and accounts for more than $96 \%$ of the total patient beds. Previous research (Shohet, Lavy 2004) studied the profile of hospital facilities in Israel based on a survey of 20 large acute-care facilities, with a total floor area of more than $1,000,000 \mathrm{~m}^{2}$, and established the average size of a hospital campus to be $76,410 \mathrm{~m}^{2}$, distributed among almost 50 buildings. The reinstatement (replacement) value of a hospital facility is $1,670 \$ / \mathrm{m}^{2}$.

Provision of healthcare services traditionally occurs through a network of both regional and principal hospital facilities. The capital reinstatement (replacement) value of a hospital is $\$ 1,800-3,300$ per $\mathrm{m}^{2}$ and the annual maintenance expenditure required to maintain these facilities is $\$ 35-54$ per $\mathrm{m}^{2}$ depending on the level of performance provided (Shohet et al. 2003). Sixty percent of the resources for maintenance are devoted to labor, and therefore the maintenance departments 
in hospitals are intensively driven by labor. Furthermore, these facilities are highly sensitive to failures in critical systems such as medical gas, and power supply.

Technology can now export sophisticated diagnostic and treatment services from the hospital setting to off-site facilities by exploiting internet connections such as PACS (Picture Archiving Computer Systems) and EMR (Electronic Medical Record) for the transfer of test results and video links (Coker et al. 2010; Fraser et al. 2005; Speedie et al. 2008). This migration of services reduces the inhouse requirements for hospital facilities and could reduce the costs of facilities that still provide a full spectrum of in and outpatient services. For example a system of care sites (or outpatient centers) separate from hospitals and close to the community could be established as a means of maintaining patient convenience, particularly in urban settings. Eight selected KPIs were evaluated in a clinic vs. hospital setting in the Israeli healthcare system and this paper discusses the implications on the economics and performance of healthcare built facilities arising from the results of the analysis.

\section{KEY PERFORMANCE INDICATORS IN HOSPITAL AND CLINIC FACILITIES}

Several key performance indicators described in the literature have been developed for hospital buildings. Pullen et al. (2000) discussed seven KPIs appropriate for hospital facilities, where most dealt with business and financial performance, and thus are mainly applicable to privatesector hospitals. The eight KPIs employed in this study are based on Shohet et al. (2003) and Lavy and Shohet (2004), as developed for hospital facilities in Israel. The KPIs used were selected from three categories, to enable an integrated analysis of the maintenance of the facilities from a life-cycle design perspective (Asset Development), effective management (Maintenance Management), and performance control (Performance Management). This allows a snap-shot cross-sectional evaluation of healthcare facilities by simultaneous analysis of the performance, the management effectiveness, and the maintenance cost-effectiveness. Each KPI described below is followed by a description of the results found in the clinics as well as in the hospital facilities evaluated in Israel.

Table 1 describes the sample population of clinics and hospital facilities analyzed in this research. The 42 clinics offer various services and
Table 1. Comparative profile of hospital and clinic facility sample

\begin{tabular}{|c|c|c|}
\hline \multirow[t]{2}{*}{ Parameter } & \multirow{2}{*}{$\begin{array}{l}\text { Clinics } \\
\text { Mean (S.D.) }\end{array}$} & \multirow{2}{*}{$\begin{array}{l}\text { Hospitals } \\
\text { Mean (S.D.) }\end{array}$} \\
\hline & & \\
\hline Sample size & 42 & 20 \\
\hline Built Floor Area $\left[\mathrm{m}^{2}\right]$ & $1,154(1,148)$ & $76,410(65,130)$ \\
\hline $\begin{array}{l}\text { Built Floor Area per } \\
\text { insured }\left[\mathrm{m}^{2}\right]\end{array}$ & 0.15 & 0.30 \\
\hline Age [years] & $7.9(6.1)$ & $27.3(19.1)$ \\
\hline Age Coefficient & $0.75(0.23)$ & $1.27(0.07)$ \\
\hline $\begin{array}{l}\text { Annual Density/ } \\
\text { Occupancy (\%) }\end{array}$ & $147(71)$ & 89 (19) \\
\hline $\begin{array}{l}\text { Density/Occupancy } \\
\text { Coefficient }\end{array}$ & $1.16(0.15)$ & $0.97(0.07)$ \\
\hline Facility Coefficient & $0.97(0.34)$ & N/A \\
\hline $\begin{array}{l}\text { Reinstatement } \\
\text { (Replacement) Value } \\
{\left[\$ / \mathrm{m}^{2}\right]}\end{array}$ & 1,180 & 1,678 \\
\hline $\begin{array}{l}\text { Annual Maintenance } \\
\text { Expenditure (AME) } \\
{\left[\$ / \mathrm{m}^{2}\right]}\end{array}$ & $24.2(13.7)$ & $37.2(5.3)$ \\
\hline $\begin{array}{l}\text { Analytical AME in \% of } \\
\text { Reinstatement Value }\end{array}$ & 2.50 & 3.23 \\
\hline $\begin{array}{l}\text { Maintenance Sources } \\
\text { Ratio (MSR) }\end{array}$ & $60.0 \%$ & $36.7 \%$ \\
\hline $\begin{array}{l}\text { Managerial Span of } \\
\text { Control (MSC) }\end{array}$ & $6.1(1.9)$ & $3.5(2.2)$ \\
\hline BPI & $95.5(2.9)$ & $76.6(5.9)$ \\
\hline MEI & $0.30(0.16)$ & $0.43(0.05)$ \\
\hline
\end{tabular}

are a representative sample of the 1,000 clinics across the country with respect to geographical and regional location and size, ranging from small clinics (floor area $<500 \mathrm{~m}^{2}$ ), medium size clinics (floor area between 500 and $1,500 \mathrm{~m}^{2}$ ), to large clinics (floor area greater than $1,500 \mathrm{~m}^{2}$ ). The mean floor area of the clinics is $1,154 \mathrm{~m}^{2}$, representing an average floor area of 0.15 per insured subscriber, while the average floor area of a hospital is $76,410 \mathrm{~m}^{2}$ representing an average of $0.30 \mathrm{~m}^{2}$ per insured subscriber.

\subsection{Asset development}

This category includes a set of KPIs that quantify the effects of the service conditions on the facility and predict the resources required to maintain the facility at its designated level of performance.

\subsubsection{Age coefficient}

The Age Coefficient $\left(A C_{y}\right)$ is defined as a coefficient for the adjustment of maintenance needs for each particular year with respect to the mean annual expenditure along the designed life cycle $(D L C)$ of the facility. A $D L C$ of 50 years was assumed for 


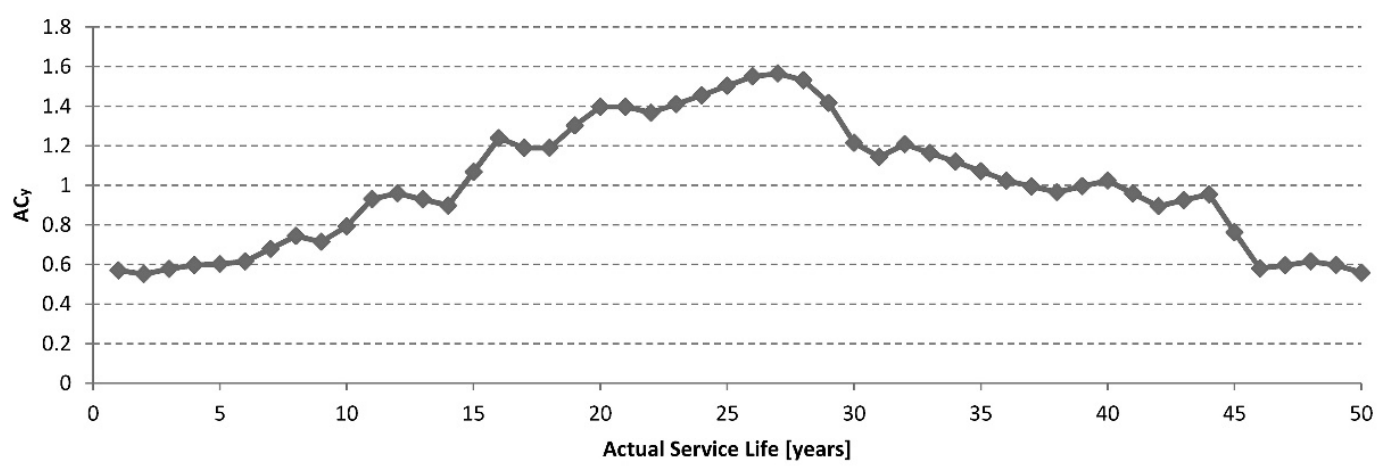

Fig. 2. Age coefficient $\left(A C_{y}\right)$ vs. actual service life of a clinic for a $D L C$ of 50 years

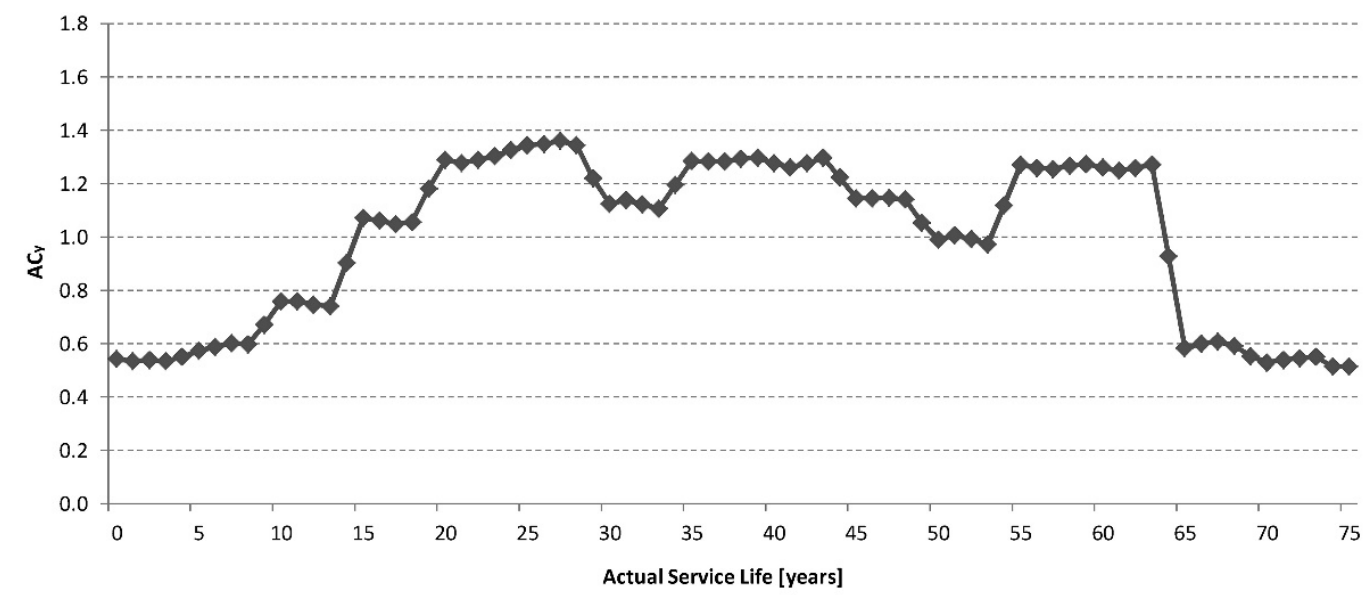

Fig. 3. Age coefficient $\left(A C_{y}\right)$ vs. actual service life of a typical hospital for a $D L C$ of 75 years

clinic facilities and 75 years for hospital facilities calculated from the following equation:

$$
\begin{aligned}
& A C_{y}=\frac{\sum_{y-4}^{y+4} A M E_{Y}+\frac{1}{2}\left(A M E_{y-5}+A M E_{y+5}\right)}{10^{*} A M E_{\text {ave. }}}, \\
& \forall y=6,7,8, \ldots, D L C
\end{aligned}
$$

where: $A C_{y}$ - Age Coefficient for year $y ; A M E_{y}-$ Annual Maintenance Expenditure for year $y ; y-$ Counter of year during the life of the building service; $A M E_{\text {ave }}$ - Average Annual Maintenance Expenditure during the $D L C$ of the facility in $\$$ per $\mathrm{m}^{2}$;

Assessment of the above coefficient for a clinic facility with $D L C$ of 50 years produced the following results (Fig. 2): $A M E_{y}=1$ represents the average maintenance expenditure $(2.5 \%$ of reinstatement (replacement) value) during the $D L C$ of the clinic. The total area below the graph equals 50. The graph has a maximum in the middle of the facility's $D L C$, indicating replacements of major components of electro-mechanical systems (e.g. electric boards, switch gears, HVAC units), and multiple local maxima indicating renovation of the clinic's interior finishing. The age coefficient for a typical hospital facility with a $D L C$ of 75 years was calculated in a similar manner. The average annual maintenance expenditure $\left(A M E_{\text {ave }}\right)$ during the $D L C$ was found to be $3.23 \%$ of the reinstatement (replacement) value. Figure 3 shows the age coefficient for the hospital buildings. The longer $D L C$ resulted in a life cycle pattern with three maxima, indicating periods that represent major renovations of the electro-mechanical infrastructures of the hospital. The average age of the hospital facilities in this sample is 27 years and the mean age coefficient is 1.27 , while the average age of the buildings of the clinics in the sample is 7.9 years with an average age coefficient of 0.75 . These results mean that the clinic facilities required $25 \%$ less resources than the $\left(A M E_{\text {ave }}\right)$ during the service life whereas the hospital facilities in the sample required a surplus of $27 \%$ compared to the hospital $A M E_{\text {ave }}$.

\subsubsection{Occupancy/density coefficients}

The research hypothesis is that density (in clinics) and occupancy (in hospitals) conditions affect the deterioration pattern of the building components and systems. The occupancy/density coefficients 
were developed through analysis of the life cycle of building components under intensive or moderate service conditions. The results indicated the following:

These coefficients quantify the effects on the deterioration of building components of the density of patients in the clinic and the occupancy of patient beds in hospitals. The standard density in clinics is defined as 175 patients per $\mathrm{m}^{2}$ per annum and is referenced as $100 \%$ density of patients. The equivalent parameter in hospital facilities is defined as occupancy; and is represented by the number of 10 patient-beds per $1,000 \mathrm{~m}^{2}$ built. These ranges are derived from the average of the populations of clinics and hospital facilities respectively.

In clinic facilities, the density coefficient was based on an analysis of the life cycle of building components under intensive vs. normal service conditions.

- In moderate density conditions (less than or equal to $80 \%$ of standard density) the density coefficient equals 0.97 , representing only minor savings in the maintenance activities, due to compulsory preventive policy.

- Between $80 \%$ and $100 \%$ relative density, the increase in maintenance activities is moderately linear with a slope of 0.001625 ;

- Between 100\% and 154\% relative density, there is a greater impact of patient density on maintenance expenditure as the slope of the graph increases to 0.00578 , and the density coefficient in high density conditions remains constant at a level of 1.31.

In hospital facilities the occupancy coefficient is defined between the range of $80 \%$ and $133 \%$ of the standard occupancy (10 patient beds per $1,000 \mathrm{~m}^{2}$ ); at low occupancy the resources required are 0.95 , while at the high levels of occupancy the coefficient is 1.22 . These ranges were found by empirical study of hospital wards under standard and intensive service conditions (Shohet et al. 2003).

The annual number of visitors per $\mathrm{m}^{2}$, representing the density in the sample of clinics is 258.0. In light of the latter finding, we deduce that the sample facilities represent intensive service conditions.

The average occupancy coefficient in the hospital facilities sample was found to be 0.97 indicating a standard occupancy of the hospital facilities with reference to the norm $\left(100 \mathrm{~m}^{2}\right.$ per patient bed).

\subsubsection{Facility coefficient FAC $_{\mathbf{y}}$}

The age and occupancy/density coefficients are integrated into a third KPI, the facility coefficient that expresses the maintenance resources required for implementing preventive and breakdown maintenance based on the facility's level of occupancy, age, type of environment, and the complexity of the buildings in terms of their components. The facility coefficient is computed through an assessment of four variables: age of the building, service conditions (occupancy/density), category of environment (marine or inland), and type of building. Typical deterioration patterns obtained from empirical research are translated into maintenance activities that are expressed in this financial coefficient as a means to adjust the maintenance resources to prevailing conditions (Lavy, Shohet 2007).

The average facility coefficient in the sample of clinics is 0.97 , indicating a standard effect of the service conditions in the clinics. Typically, a hospital campus consists of multiple buildings (unlike clinics, which is a single, in most cases standalone, building), and so the facility coefficient for hospital facilities is not available at this time.

\subsection{Maintenance management}

This category of KPIs provides insight into the organizational procurement and costs of maintenance services; three KPIs described below were developed under this category: annual maintenance expenditure $(A M E)$, maintenance sources ratio $(M S R)$, and managerial span of control (MSC).

\subsubsection{Annual maintenance expenditure (AME)}

This KPI reflects the scope of expenditure per $\mathrm{m}^{2}$ built (excluding cleaning, energy, and security expenditures). From an organizational viewpoint, this parameter determines the annual expenditure on maintenance of a clinic/hospital; and provides a means to assess the overall expenditure on built assets with reference to the organization's turnover. From a managerial-professional viewpoint, however, the expenses must be analyzed in relation to the facility's characteristics and with respect to the output (the physical performance). This examination is achieved in the framework of the maintenance efficiency indicator ( $M E I)$, as described below. The desirable range of $A M E$ for hospital and clinic facilities was determined by analysis of the different maintenance activities, both preventive, and breakdown required to maintain the facilities at an acceptable performance level (Shohet 2003; Shohet et al. 2008; Shohet, Nobili 2017).

The mean $A M E$ for the maintenance of the clinics in the sample population is $\$ 24.2$ per $\mathrm{m}^{2}$, constituting an annual expenditure of $2.05 \%$ of the re-instatement value of the clinics $\left(\$ 1,180\right.$ per $\left.\mathrm{m}^{2}\right)$. This is lower than the analytical expectancy of 
$2.5 \%$ of the reinstatement (replacement) value. In light of the low age of the clinic sample (7.9 years), this level of expenditure is high and may be explained by the intensive service conditions of the clinic facilities as discussed above.

The average $A M E$ for the hospital buildings was $\$ 37.2$ per $\mathrm{m}^{2}$ (in 1999 values), with a standard deviation of $\$ 5.3$ per $\mathrm{m}^{2}$ constituting $2.22 \%$ of the re-instatement value of a hospital facility. This finding represents scarcity of resources since the desired level for a typical hospital is $3.23 \%$ as described above.

\subsubsection{Maintenance sources ratio (MSR)}

Outsourcing constitutes an alternative strategy to procuring maintenance activities by in-house employees, who require ongoing management. Outsourcing can be useful for the execution of seasonal preventive maintenance work, as well as for rehabilitation, renovation, and replacement works. This parameter reflects the ratio of external maintenance resources to the total sum of resources, and expresses the extent of outsourcing (in \%) out of the total resources allocated for maintenance of the facility. Previous studies found that outsourcing may contribute to savings of approximately $10 \%$ compared to in-house provision (Domberger, Jensen 1997). A combination of $60 \%$ outsourcing with $40 \%$ internal labor may represent a solid balance in healthcare facilities located in a large urban area under standard service conditions.

The $M S R$ in the sampled clinics shows that $60 \%$ of the services are contracted out.

The MSR in the hospitals shows that $36.7 \%$ of the resources are contracted out. This distribution emphasizes the dependence of hospital facilities on in-house labor, with the accompanying advantages of familiarity with the local conditions, availability at the job site and accountability.

\subsubsection{Managerial span of control (MSC)}

Managerial Span of Control (MSC) is one of the managerial key parameters that indicate how effectively an organization achieves coherence among its units (Mintzberg 1989). This indicator is defined as the ratio between the number of managers and the number of personnel directly subordinated to them. While a wide span of control may save overhead expenses, it sometimes creates managerial difficulties. In contrast, while a narrow span of control may minimize the amount of routine coordination required and leave time for the manager to deal with planning, overhead expenses are usually high. In hospitals the definition of this indicator is straightforwardly, but for clinics, the geographical dispersion and the size may result in a hierarchical management where several facilities located in a close regional area come under the direction of a regional facility manager. The $M S C$ is then defined as the number of clinic facilities subordinated to the supervision of a regional FM. At small spans of $M S C(M S C<6)$, the managerial overhead costs per clinic rise as some of the managerial resources may be redundant, while larger values of $M S C$ (i.e. $M S C>8$ ) reduce the costs of managerial overhead, although the effectiveness of supervision may be diminished (Laufer, Shohet 1991).

The average $M S C$ for the regional FM in the sampled clinics is 7.2 compared with a normative span of 6 . This difference is explained by the relatively small sizes of the sampled facilities.

In the hospital sample, it was observed that the principal engineer managed 3.5 direct subordinates on average. Second level managers, mainly engineers or experts in the different maintenance disciplines (e.g., electrical, mechanical, water supply and waste water), supervised 7.1 subordinates on average. These numbers are in accordance with the literature, allowing the principal engineer to dedicate an appropriate amount of time to planning issues, while the second level managers are usually kept busy with the operation of the facility.

\subsection{Performance management}

The performance section of KPIs covers the physical performance of built facilities as well as the efficiency with which the allocated resources for maintenance are utilized, as follows.

\subsubsection{Building performance indicator (BPI)}

This KPI enables the evaluation of the overall state of a clinic or of a hospital building, according to the physical performance of its components and systems. The indicator is expressed as a value between 0 and 100 that reflects the state of the building, including the performance of its various systems $\left(P_{n}\right) . P_{n}$ is graded between 0 and 100 according to performance scales, where $P_{n}<60$ indicates a poor/dangerous performance, $60<P_{n} \leq 70$ indicates a deteriorating performance, $70<P_{n} \leq 80$ indicates a marginal (71) or satisfactory (80) condition, and $P_{n}>80$ indicates a good condition. The performance scores for each system were assessed by the data gathered using Supplementary Appendix 1 and the performance ratings by using the scales in Supplementary Appendix 2. The actual 
score for each system $\left(P_{n}\right)$ is expressed by Equation (2) and includes three composites of facility maintenance: (1) the actual condition of the system $\left(C_{n}\right)$; (2) failures affecting the service provided by the components of the system $\left(F_{n}\right)$; and (3) actual preventive activities carried out on the system to maintain an acceptable service level $\left(P M_{n}\right)$ (Israel Standards Institution 2011).

$$
P_{n}=C_{n} \cdot W(C)_{n}+F_{n} \cdot W(F)_{n}+P M_{n} \cdot W(P M)_{n},
$$

where: $W(C)_{n}$ - weight of component condition of system $n ; W(F)_{n}$ - weight of failures in system $n$; $W(P M)_{n}$ - weight of preventive maintenance for system $n$.

For every system $n$, the sum $W(C)_{n}+W(F)_{n}+$ $W(P M)_{n}$ totals 1 . The score $C_{n}$ is evaluated according to the grading scale as demonstrated in Supplementary Appendix 2. Frequency of failures $\left(F_{n}\right)$ is evaluated on a scale between $100=$ no failure (incidents of breakdown maintenance) in 12 months, and $20=$ frequent occurrence (e.g. 12 times in the last 12 months in a roofing system). Preventive Maintenance $\left(P M_{n}\right)$ is evaluated on the basis of maintenance policy governing the component, and the frequency of pro-active inspections and periodical maintenance carried out with respect to standards. The combination of these three elements produces the performance score for the entire system $\left(P_{n}\right)$. Weighting of each building system $\left(W_{n}\right)$ in the $B P I$ is accomplished by a consideration of the contributions of the system's components to the life cycle costs.

Once the systems' performance states have been diagnosed, the BPI is calculated for each system by multiplying the weight by its score (Eq. (3)):

$$
B P I=\sum_{n=1}^{10} P_{n} X W_{n} .
$$

The desired BPI range is above 80 , and any system or component with a score below 70 requires corrective maintenance measures. The desirable range was deduced from the definitions of the scales, and from analysis of samples of hospitals, clinics, and office buildings (Shohet 2006).

This parameter enables us (1) to evaluate the overall state of a facility; (2) to evaluate the state of the facility's systems; (3) to benchmark the asset's performance in relation to other facilities (inter-organizational benchmarking); and (4) to benchmark the systems of the clinic or hospital in order to compare the efficiency of the various maintenance crews (intra-organizational benchmarking).

Table 2 shows the mean performance scores and their standard deviations for each of ten sys-
Table 2. Performance scores of building systems in the sample of public acute-care hospitals and clinics

\begin{tabular}{llll}
\hline Building system & \multicolumn{1}{l}{ Clinics } & & Hospitals \\
& Mean (S.D.) & & Mean (S.D.) \\
\hline Sample size & 42 & 20 \\
Structure & $94.4(3.1)$ & $79.9(6.1)$ \\
Exterior envelope & $92.6(5.5)$ & $74.4(10.1)$ \\
Interior finishes & $93.6(4.6)$ & $76.2(8.8)$ \\
Electricity & $97.4(3.0)$ & $77.8(6.9)$ \\
Sanitary system & $92.7(5.1)$ & $69.9(9.9)$ \\
HVAC & $94.1(4.5)$ & $77.0(7.1)$ \\
Fire protection & $100.0(0.0)$ & $76.6(14.2)$ \\
Elevators & $96.2(2.9)$ & $79.6(5.7)$ \\
Communications and & $99.4(2.0)$ & $82.2(10.1)$ \\
low-voltage & & \\
Medical gases & N/A & $87.5(10.5)$ \\
Total $(B P I)$ & $95.5(2.9)$ & $76.6(5.9)$ \\
\hline
\end{tabular}

tems in acute-care hospital buildings and for nine building systems in clinic buildings. The mean value of $B P I$ in the clinics was found to be 95.5 , which indicates a high performance of the facilities in the sample. The relatively small variance of this parameter indicates its high significance.

The average $B P I$ in the sampled hospital facilities was 76.6 with a standard deviation of 5.9. This indicates that the level of performance of the facilities was only satisfactory. Notably, only four facilities were found to be performing at a "good" level of performance (BPI of 80 or more). On average, the system with the highest performance was identified as medical gases (87.5 points out of 100), while the system with the lowest performance score was found to be the sanitary system (69.9 points).

\subsubsection{Maintenance efficiency indicator (MEI)}

This indicator examines the allocation of resource for maintenance in relation to the facility's performance. The MEI is calculated by Equation (4):

$$
M E I=\frac{A M E_{y}}{F A C_{y}} \cdot \frac{1}{B P I} \cdot i_{c},
$$

where: $A M E_{y}$ - actual Annual Maintenance Expenditure; $F A C_{y}-$ Facility Coefficient for year $y$; $B P I$ - monitored Building Performance Indicator; $i_{c}$ - construction prices index.

This indicator expresses the expenditure on maintenance per hospital/clinic performance unit, adjusted to prevailing conditions using the $F A C_{y} . M E I$ may be analyzed in the two dimensional system of $B P I$ (dependent variable) and the Normalized Annual Maintenance Expenditure 
$\left(N A M E_{y}\right)$ (independent variable) as expressed in Equation (5):

$$
N A M E_{y}=\frac{A M E_{y}}{F A C_{y}} .
$$

$N A M E_{y}$ expresses the Annual Maintenance Expenditure neutralized from the effects of age $\left(A C_{y}\right)$, the facility's occupancy/density (OC or DC), and environmental conditions through the Facility coefficient. The NAME forms a clear and transparent perspective to the $A M E_{y}$, from which the $M E I$ can be easily interpreted.

For a clinic facility maintained at the desired performance level, we assume a BPI of 100 . The average $A M E_{y}$ per $\mathrm{m}^{2}$ was calculated to be $2.50 \%$ of the reinstatement (replacement) value of a clinic facility which was calculated to be $\$ 1,180$ per $\mathrm{m}^{2}$ built. A clinic facility with an Age Coefficient of 1.00 (the standard), a Density Coefficient of 1.00 and a consequent facility coefficient of 1.00 would yield an $M E I$ value of 0.30 . The $M E I$ values are thus interpreted according to the following categories:

- $M E I<0.24$ indicates that the resources are utilized at high efficiency, or scarcity of resources for maintenance, or both;

- $0.36 \leq M E I \geq 0.24$ reflects a normative range of maintenance efficiency, in which the lower limit indicates good efficiency while the upper limit indicates low efficiency and/or surplus of resources; and

- $M E I>0.36$ indicates a high level of resources relative to the actual performance. Such a high value may reflect high maintenance expenditures, low physical performance, or a combination of these two extreme situations.
Ranges for the $M E I$ in hospital facilities were deduced in a similar manner. Three ranges for $M E I$ were established for hospital facilities in Israel:

- $M E I<0.37$ reflecting high maintenance resource utilization efficiency, and/or lack of resources;

- $0.52 \leq M E I \geq 0.37$ indicating normative use of maintenance resources; and

- $M E I>0.52$ indicating high input in comparison with the actual performance, and/or surplus of resources.

The upper and lower boundaries of the $M E I$ for the clinic and hospital facilities were deduced from a coefficient of variance of 0.2 aimed at creating a homogeneity and low variance.

The mean $M E I$ in the sample of clinics falls within the predicted analytical value (0.30), and the variance indicated significant variability in this parameter. This level of efficiency was established following a two year corrective and preventive maintenance policy that used the $B P I$ as a key measure for establishing a maintenance policy.

Figure 4 shows the distribution of the clinic facilities sample in a two dimensional setting where the independent variable is the NAME and the dependent variable is the $B P I$. The three lines represent equivalent levels of efficiency, defined for clinics, where $M E I=0.30$ is the normative, $M E I=0.36$ represents the highest margin of the normative efficiency range of maintenance, i.e. higher values represent high expenditure, indicating low efficiency and surplus of resources and $M E I=0.24$ reflects efficient execution of maintenance. Facilities with an $M E I$ lower than 0.24 lack resources. The distribution validates the predicted ranges deduced from the analytical development

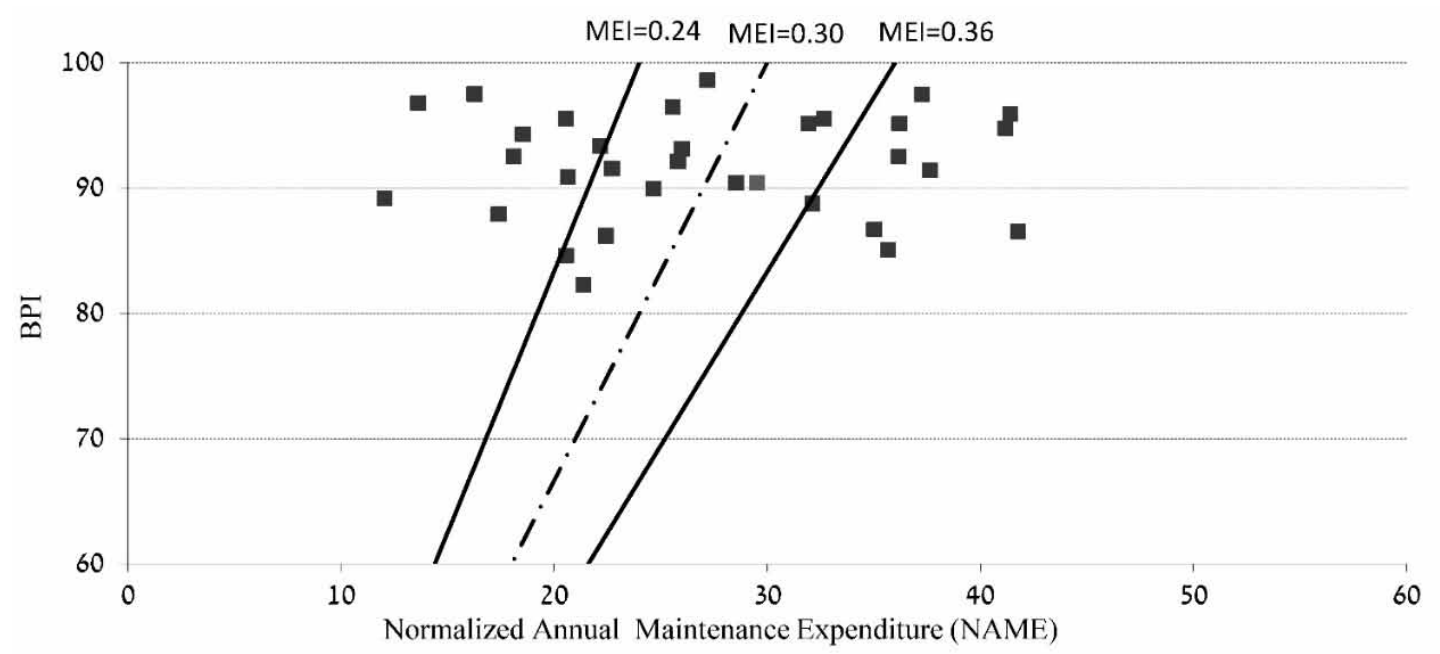

Fig. 4. Building Performance Indicator (BPI) against Normalized Annual Maintenance Expenditure $(N A M E)$ for the sample of clinics 


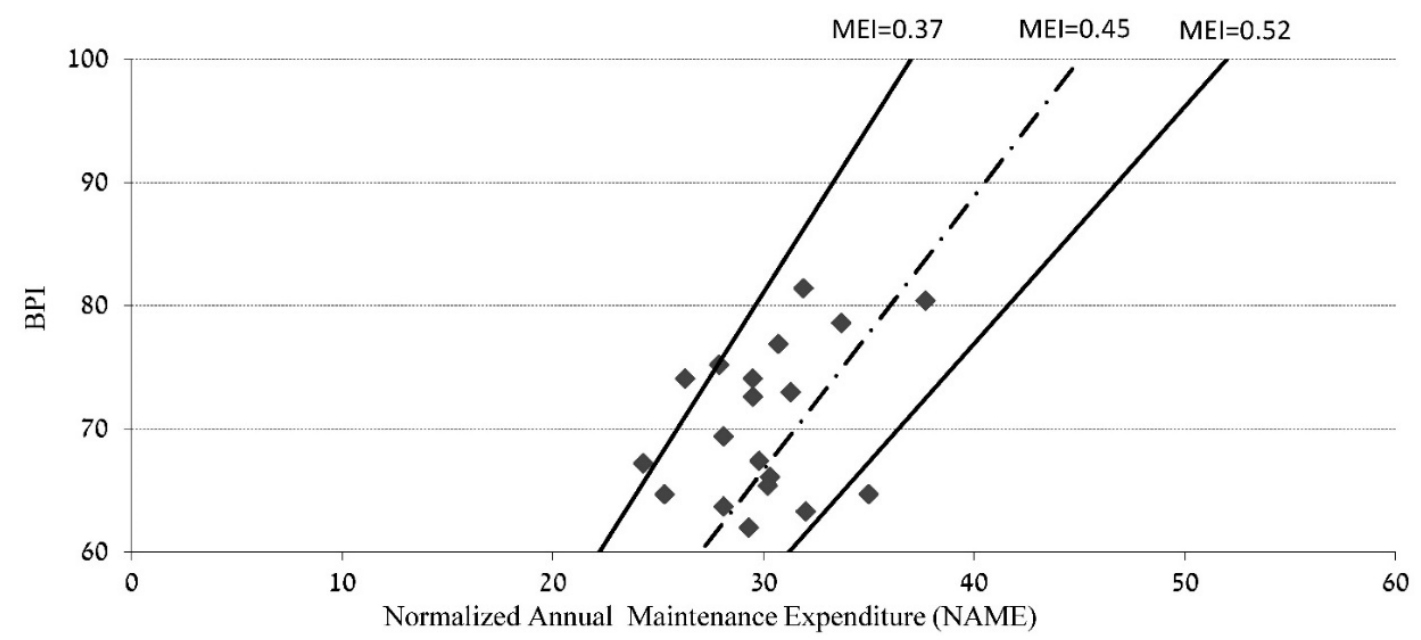

Fig. 5. Building Performance Indicator $(B P I)$ vs. Normalized Annual Maintenance Expenditure (NAME) for hospital buildings

of this parameter. Facilities that are found close to the left margin $(M E I=0.24)$ exemplify the high efficiency with which the maintenance resources are used, whereas facilities found close to or beyond the right margin $(M E I=0.36)$ require further analysis to uncover the sources of inefficiency and to establish outlines for an improvement program.

A distribution of the observed $M E I$ in the hospital sample is shown in Figure 5, on a $B P I$ vs. $N A M E$ graph. The average $M E I$ in hospitals was found to be 0.43 , which represents a fair use of maintenance resources since it is in the normative range (between 0.37 and 0.52 ). It is more than reasonable to assume that some of these expenses could have been saved if a larger share of the work had been given to external service providers.

\subsubsection{Number of employees}

The total number of employees (physicians, nurses, administrative and technical staff) was evaluated vs. the clinic built floor area. There was a linear correlation between the number of employees (dependent variable) and the clinic's built floor area (independent variable), with a correlation coefficient of 0.76 . Regression analysis expressed in Equation (6) and Figure 6, shows a linear correlation between the number of employees and the built floor area:

$$
W=0.0443 Z+6.5863,
$$

where: $W$ - Number of employees in a clinic; $Z-$ Clinic built floor area $\left(\mathrm{m}^{2}\right)$.

This regression is valid for clinics with a built floor area between 100 and $4,500 \mathrm{~m}^{2}$. The total number of employees (physicians, nurses, and staff) was also consistent to a certain extent, and there was a linear correlation between the num- ber of employees (dependent variable) and the number of patient beds (independent variable), with a correlation coefficient of 0.86 . Regression analysis shows a linear correlation expressed in Equation (7) and Figure 7, between the number of employees and the number of patient beds:

$$
Y=3.25 X-208.6 \text {, }
$$

where: $\mathrm{Y}$ - Number of employees in the acute care hospital; X - Number of Patient Beds in the acute care hospital.

The regression shows that 766 employees are required (2.55 employees per patient bed) for facilities with 300 patient beds. Each additional patient bed necessitates an average supplement of 3.25 jobs. It should be stressed that this regression is valid for the range between 300 and 1,300 patient beds in public acute-care hospitals. Moreover, it was found that these hospitals had, on average, 2.86 employees per patient bed, with a standard deviation of 0.74. Concerning maintenance staff, there were 47.6 maintenance employees, on average, per hospital. Furthermore, there were found to be on average 14.6 patient beds per internal maintenance employee, with a standard deviation of 3.3. Alternatively, this number can be expressed as an average of 0.63 employees per $1,000 \mathrm{~m}^{2}$ of hospital floor area, with a standard deviation of 0.18 (which means one internal maintenance employee per $1,587 \mathrm{~m}^{2}$ of floor area). It should be emphasized that the average number of maintenance employees per hospital facility is strongly affected by the policy regarding the employment of in-house manpower vs. outsourcing of maintenance services. The relatively high standard deviations reflect the diversity of the sample population with regard to this policy in almost all maintenance fields. On 


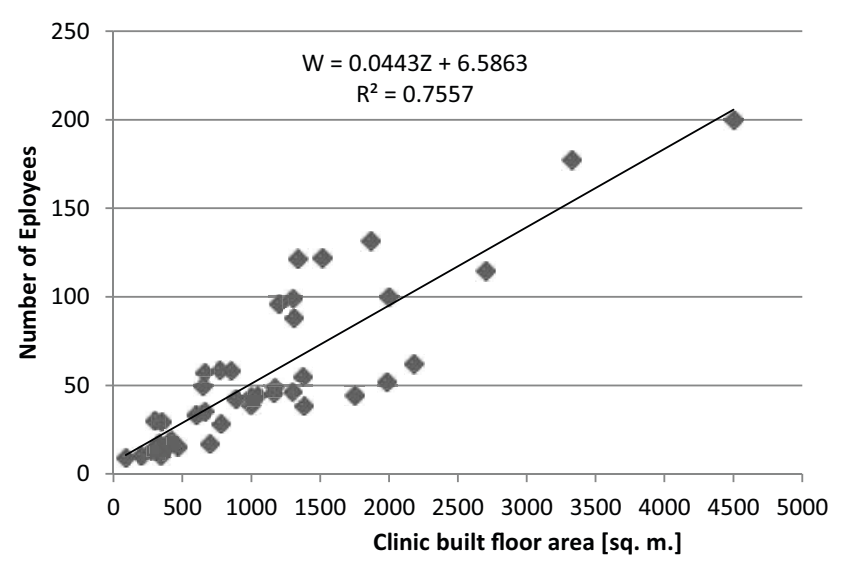

Fig. 6. Number of employees vs. clinic built floor area $\left(\mathrm{m}^{2}\right)$

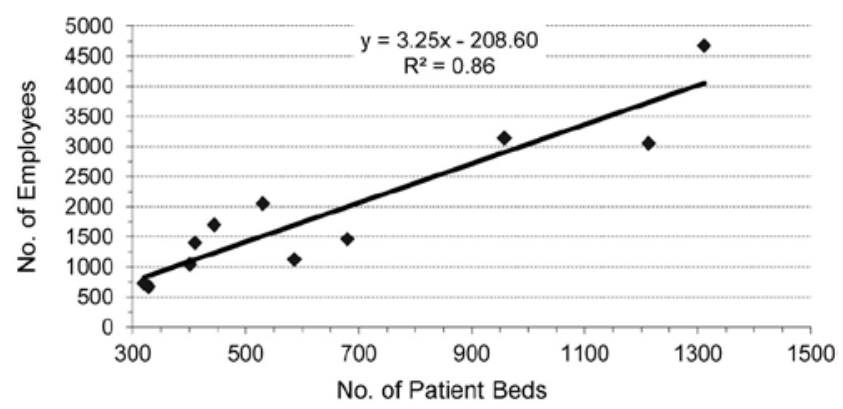

Fig. 7. Number of employees vs. number of patient beds in acute-care hospitals

average, the largest in-house maintenance crews are in the fields of electricity, air-conditioning, and water and plumbing, which are considered to be the core areas of maintenance in hospital facilities. In contrast elevators, fire protection, and waterproofing were maintained exclusively contracted out due to the high availability of outsourced workers in these areas and their low cost.

\section{CONCLUSION}

Global indicators may show that the Israeli healthcare system succeeds in providing solid healthcare services although the annual investment per capita on healthcare is in decline. A comparative review of the selected hospital and clinic facilities revealed considerable differences between the facilities in terms of FM parameters. While hospital facilities necessitate the allocation of double the amount of resources for maintenance and the computed annual expenditure for hospitals required to accomplish full performance is $\$ 54$ per $\mathrm{m}^{2}$ (3.23\% of the reinstatement (replacement) value) compared with $\$ 29$ per $\mathrm{m}^{2}$ (2.5\% of reinstatement (replacement) value) in clinics, accomplishing high performance for hospital built-facilities is complex. The BPI for clinics (95.5) indicates a high level of achievement of the performance goals of the maintenance policy in clinics, compared with marginal performance accomplished in hospitals (76.6). This includes the physical performance of the facility as well as the ability to address the needs of the users (medical staff and patients). Furthermore, the built-floor area per insured patient in clinic facilities in Israel $\left(0.15 \mathrm{~m}^{2}\right)$ falls far below the equivalent parameter for acute-care hospitals $\left(0.30 \mathrm{~m}^{2}\right)$; thus, the actual expenditure per insured patient in a hospital is nearly four times higher than in a clinic. A comparison of the total number of employees per insured patient in a typical clinic or hospital indicates that the total number of employees in clinics is $17 \%$ lower than in hospitals.

Community clinics are much more accessible than peripheral or regional hospitals in terms of geographical dispersion. Accomplishment of available care is realized to a greater extent and the cost of facilities per insured subscriber is approximately $75 \%$ lower than in regional hospitals. From a life cycle perspective, the maintenance of hospital facilities involves two critical life-supporting systems (electricity and medical gas), and three additional electro-mechanical systems that support healthcare and hygiene (communication and low voltage, water supply and sanitary, and HVAC).

The above comparative view of KPIs reveals that delivery of part of the healthcare services through clinics has multiple advantages from the FM point of view:

- Clinic facilities provide a high potential for combining improved healthcare facility services with cost-effective facility management and maintenance;

- The capital cost invested per patient is considerably less.

Since hospitals are more expensive buildings to maintain than community clinics, a migration of services can be expected to make it possible to reduce the cost of facilities for a healthcare system that delivers a full range of in- and outpatient services. The utilization of clinic facilities for primary care, instead of peripheral and regional hospital facilities, has a potential for flexible infrastructure and for close healthcare. This leads to a prediction that a future hospital will be composed of the core of medical acute care connected to a network of community and regional clinics providing primary care and serving both as close care providers and as a screening net for patients requiring the services of the core hospital. This scenario would greatly 
increase the importance of future community clinics and the services provided in these clinics will be extended through the use of telemedicine, to include primary and emergency care, as well as diagnostic services and specialty care.

The findings indicate that the delivery of healthcare through community clinics may be a key means to address the need for improving healthcare facilities services both in low and in highincome countries (Stanowski et al. 2015; Kapongo et al. 2015). Implications of the present study for the global healthcare system infer that the role of clinics facilities in healthcare delivery should be increased, as clinics facilities provide cost-effective robust performance to HMOs (Healthcare Maintenance Organizations).

Further research regarding the performance and cost-effectiveness of hospital vs. clinic facilities is recommended in Africa, Asia, Europe, North and South-America and in order to validate, elaborate, and implement the potential findings of this study in the global healthcare system.

\section{REFERENCES}

American Hospital Association. 2004. TrendWatch chartbook 2004: trends affecting hospitals and health systems - September 2004 [online]. American Hospital Association. Available at: http://www.aha.org/ research/reports/tw/chartbook/2004chartbook.shtml [accessed August 2015]

American Hospital Association. 2006. 2006 AHA policy research [online]. American Hospital Association. Available at: http://www.aha.org/research/policy/2006.shtml [accessed March 2015]

American Hospital Association. 2010. Chartbook 2010 chapter 3: utilization and volume [online]. American Hospital Association. Available at: http://www.aha. org/research/reports/tw/chartbook/2010/chapter3.pdf [accessed March 2015]

British Ministry of Finance. 2003. Budget 2003: reportchapter 6: delivering high quality public services [online]. British Ministry of Finance. Available at: http://www.hm-treasury.gov.uk/budget/bud_bud03/ budget_report/bud_bud03_repchap6.cfm [accessed February 2005]

Brodsky, J. 2003. The challenges of a success: the ageing of Israeli society, Israel Medical Association Journal 5(5): 375-378.

Central Bureau of Statistics in Israel. 2009. Beds in hospitals, by ownership and type of bed [online]. Central Bureau of Statistics in Israel. Available at: http://www.health.gov.il/download/docs/units/comp/ ma2009/part2/C1.pdf [accessed March 2015]

Ciarapica, F. E.; Giacchetta, G.; Paciarotti C. 2008. Facility management in the healthcare sector: analysis of the Italian situation, Production Planning \& Control 19(4): 327-341.

https://doi.org/10.1080/09537280802034083
Cingolini, F.; Fedele, L.; Villa, A. N. 2008. Managing facilities under the multi-service result-oriented approach: some insights coming from the field in Italy, Production Planning and Control 19(4): 321-326. https://doi.org/10.1080/09537280802034075

Coelho, K. R. 2011. Identifying telemedicine to improve access to specialty care for the undeserved in the San Francisco safety net, International Journal of Telemedicine and Applications, 2011: Article ID 523161. https://doi.org/10.1155/2011/523161

Coker, T. R.; Rodriguez, M. A.; Flores, G. 2010. Familycentered care for US children with special health care needs: who gets it and why?, Pediatrics 125(6): 1159-1167. https://doi.org/10.1542/peds.2009-1994

Domberger, S.; Jensen, P. 1997. Contracting out by the public sector: theory, evidence, prospects, Oxford Review of Economic Policy 13(4): 67-78. https://doi.org/10.1093/oxrep/13.4.67

Federal Statistical Office Germany. 2003. Facilities, beds and patient turnout: hospitals 1991-2003 [online]. Federal Statistical Office Germany. Available at: http://www.destatis.de/basis/e/gesu/gesutab29. htm [accessed March 2015]

Fox, P.; Porter, P. G.; Lob, S. H.; Boer, J. H.; Rocha, D. A.; Adelson, J. W. 2007. Improving asthma-related health outcomes among low-income, multiethnic, school-aged children: results of a demonstration project that combined continuous quality improvement and community health worker strategies, Pediatrics 120(4): 902-911.

https://doi.org/10.1542/peds.2006-1805

Fraser, H. S. F.; Biondich, P.; Moodley, D.; Choi, S.; Mamlin, B. W.; Szolvitz, P. 2005. Implementing electronic medical record systems in developing countries, Informatics in Primary Care 13(2): 83-96. https://doi.org/10.14236/jhi.v13i2.585

Hensher, M.; Edwards, N. 1999. The hospital of the future: hospital provision, activity, and productivity in England since 1980, British Medical Journal 319(7214): 911-914. https://doi.org/10.1136/bmj.319.7214.911

Hosking, J. E.; Jarvis, R. J. 2003. Developing a replacement facility strategy: lessons from the healthcare sector, Journal of Facilities Management 2(3): 214228. https://doi.org/10.1108/14725960410808212

Hutchison, B.; Østbye, T.; Barnsley, J.; Stewart, M.; Mathews, M.; Campbell, M. K.; Vayda, E.; Harris, S. B.; Torrance-Rynard, V.; Tyrrell, C. 2003. Patient satisfaction and quality of care in walk-in clinics, family practices and emergency departments: the Ontario walk-in clinic study, Canadian Medical Association Journal Journal 168(8): 977-983.

Israel Standards Institution. 2011. IS-1525 (Part 2) Building maintenance management: elements and finish. Tel-Aviv, Israel (in Hebrew).

Kapongo, R. Y.; Lubelo, A. M.; Mafuta, E. M.; Mutombo, P. B.; Diembelolo, J. C. M.; Bieleli, I. E. 2015. Assessment of health service delivery capacities, health providers' knowledge and practices related to type 2 diabetes care in Kinshasa primary healthcare network facilities, Democratic Republic of Congo, BMC Health Services Research 15(9). https://doi.org/10.1186/s12913-015-0679-5 
Laufer, A.; Shohet, I. M. 1991. Span of control of the construction foreman a situational analysis, Journal of Construction Engineering and Management 117(1): 90-105. https://doi.org/10.1061/(ASCE)07339364(1991)117:1(90)

Lavy, S.; Garcia, J. A.; Dixit, M. K. 2014a. KPIs for facility's performance assessment, Part I: identification and categorization of core indicators, Facilities 32(5/6): 256-274. https://doi.org/10.1108/F-09-2012-0066

Lavy, S.; Garcia, J. A.; Dixit, M. K. 2014b. KPIs for facility's performance assessment, Part II: identification of variables and deriving expressions for core indicators, Facilities 32(5/6): 275-294. https://doi.org/10.1108/F-09-2012-0067

Lavy, S.; Shohet, I. M. 2004. Integrated maintenance management of hospital buildings: a case study, Construction Management and Economics 22(1): 25-34. https://doi.org/10.1080/0144619042000186031

Lavy, S.; Shohet, I. M. 2007. On the effect of service life conditions on the maintenance of healthcare facilities, Construction Management and Economics 25(10): 1087-1098. https://doi.org/10.1080/01446190701393034

Lega, F.; Marsilio, M.; Villa, S. 2013. An evaluation framework for measuring chain performance in the public healthcare sector: evidence from the Italian NHS, Production Planning \& Control 24(10-11): 931-947. https://doi.org/10.1080/09537287.2012.666906

Melin, A.; Granath, J. A. 2004. Patient focused healthcare: an important concept for provision and management of space and services to the healthcare sector, Facilities 22(11/12): 284-289. https://doi.org/10.1108/02632770410561277

Mintzberg, H. 1989. Mintzberg on management - inside our strange world of organizations. Hungry Minds Inc., New York, USA.

Pullen, S.; Atkinson, D.; Tucker, S. 2000. Improvements in benchmarking the asset management of medical facilities, in Proceedings of the International Symposium on Facilities Management and Maintenance, 15-17 November 2000, Brisbane, Australia, 265-271.

Qu, X.; Shi, J. 2009. Effect of two-level provider capacities on the performance of open access clinics, Health Care Management Science 12(1): 99-114. https://doi.org/10.1007/s10729-008-9083-6

Rees, D. 1997. The current state of facilities management in the UK National Health Service: an overview of management structures, Facilities 15(3/4): 62-65. https://doi.org/10.1108/02632779710160559

Rees, D. 1998. Management structures of facilities management in the National Health Service in England: a review of trends 1995-1997, Facilities 16(9/10): 254-261. https://doi.org/10.1108/02632779810229075
Scott, J. C.; Conner, D. A.; Venohr, I.; Gade, G.; McKenzie, M.; Kramer, A. M.; Bryant, L.; Beck, A. 2004. Effectiveness of a group outpatient visit model for chronically ill older health care clinic, Journal of the American Geriatrics Society 52(9): 1463-1470. https://doi.org/10.1111/j.1532-5415.2004.52408.x

Shohet, I. M. 2003. Building evaluation methodology for setting maintenance priorities in hospital buildings, Construction Management and Economics 21(7): 681692. https://doi.org/10.1080/0144619032000115562

Shohet, I. M. 2006. Strategic healthcare facilities maintenance - key performance indicators, Journal of Construction Engineering and Management 132(4): 345-352. https://doi.org/10.1061/(ASCE)07339364(2006)132:4(345)

Shohet, I. M.; Kot, N.; Karako, I. 2008. Clinics facilities maintenance using life cycle costs principles, in Proceedings of the CIB W-70 International Conference in Facilities Management, 16-18 June 2008, Heriot Watt University, Edinburgh, 259-268.

Shohet, I. M.; Lavy, S. 2004. Healthcare facilities management - state of the art review, Facilities 22(7/8): 210-220. https://doi.org/10.1108/02632770410547570

Shohet, I. M.; Lavy-Leibovich, S.; Bar-On, D. 2003. Integrated maintenance management of hospital buildings, Construction Management of Economics 21(2): 219-228. https://doi.org/10.1080/0144619032000079734

Shohet, I. M.; Nobili, L. 2017. Application of key performance indicators for maintenance management of clinics facilities, International Journal of Strategic Property Management 21(1): 58-71. https://doi.org/10.3846/1648715X.2016.1245684

Speedie, S. M.; Ferguson, A. S.; Sanders, J.; Doarn, C. R. 2008. Telehealth: the promise of new care delivery models, Telemedicine and e-Health 14(9): 964-967. https://doi.org/10.1089/tmj.2008.0114

Stanowski, A. C.; Simpson, K.; White A. 2015. Pay for performance: are hospitals becoming more efficient in improving their patient experience?, Journal of Healthcare Management 60(4): 268-284.

Talib, Y.; Rajagopalan, P.; Yang, R. J. 2013. Evaluation of building performance for strategic facilities management in healthcare, Facilities 31(13/14): 681-710. https://doi.org/10.1108/f-06-2012-0042

World Bank. 2012. World Bank data indicators [online]. World Bank, Washington, United States. Available at: http://data.worldbank.org/indicator/SH.XPD. PCAP [accessed February 2012]

World Health Organization. 2012. World health statistics, Part III - Global indicators [online]. World Health Organization, Geneva, Switzerland. Available at: http://www.who.int/healthinfo/EN_WHS2012_ Part3.pdf [accessed February 2012] 